\title{
THE PERFORMANCE OF PROFESSIONALS AND STUDENTS IN AN EXPERIMENTAL STUDY OF LOBBYING
}

\author{
Jan Potters \\ Department of Economics, Tilburg University, PO Box 90153, 5000 LE Tilburg, the Netherlands
}

\section{Frans van Winden}

CREED, University of Amsterdam, Roetersstraat 11, 1018 WB Amsterdam, the Netherlands

\begin{abstract}
This paper reports on a series of signaling game experiments in which an informed sender can send a costly message in order to persuade an uninformed responder. We compare the behavior of two subjects pools: 143 undergraduate students and 30 public affairs officials that are professionally familiar with strategic information transmission. The experiments comprised two parameter treatments: one with low costs for sending messages, and one with high costs. Our main conclusion is that there are neither significant nor systematic differences in the behavior of the two subject-pools.
\end{abstract}

January, 1996

Acknowledgments. We thank the Netherlands Organization for Scientific Research (NWO) for financial support, Public Affairs Consultants and RVAWO for the opportunity to organize the experiments with professionals, and Arthur Schram and Joep Sonnemans for their help in conducting the experiments. In addition, we acknowledge the comments by participants at the ESA/Public Choice Society Meeting in New Orleans (1992), the workshop on experimental economics in Stony Brook (1992), the Amsterdam Workshop on Experimental Economics (1992), and the IAREP Conference in Rotterdam (1994). 


\section{Introduction}

In a recent study we investigated the behavior of student subjects in a signaling game experiment designed to capture some basic features of lobbying (Potters and van Winden, forthcoming). At the heart of lobbying is the strategic transmission of information by a "sender" (lobbyist) interested in persuading a "responder" (policymaker) to choose a particular type of action (see, e.g., AustenSmith, 1994, Potters and van Winden, 1992, Strauch, 1993). In the setup chosen for the experiment the sender has private information on the realization of some stochastic state variable which affects the payoffs of both sender and responder. The responder has to make a decision which determines the payoffs of both sender and responder, given the value of the state variable. On the basis of her prior incomplete information, the responder is inclined to take a decision which is unfavorable for the sender. However, the sender can opt to send a (costly) message to the responder in an attempt to change the responder's beliefs about the state variable and induce the responder to take a decision which is preferred by the sender. As the next section will show, game theory provides sharp predictions for the outcome this game. Our experimental results clearly deviated from these predictions. On the other hand, they gave support to the hypothesis that subjects adapt their behavior to what they experience, in the direction of 'best response to history' (even though the game is of the "one shot" type).

These results may evoke the criticism that, in order to learn something about lobbying, one should not use students as subjects, because they are not familiar with the intricacies of, and have no training in, the strategic transmission of information. On a more general level, this issue of "subject surrogacy" is often raised by those who are sceptical about the results of experimental inquiry in the social sciences. Experimentalists usually rebut the argument by pointing out that it is not a criticism of the experimental method per se, but a plea for "selective replications" with professionals from the field (Kinder and Palfrey, 1993, Plott, 1982). Up till now remarkably few differences between students and professionals have been documented in the experimental literature (see, e.g., Davis and Holt, 1993, p. 17). Unfortunately, this evidence shows a number of limitations. First of all, it is based on relatively few studies, with small numbers of professionals ${ }^{1}$. Secondly, in contrast with standard procedures for student subjects, subjects in these studies are sometimes not paid at all (e.g., Burns, 1985), or not in the usual fashion (e.g., DeJong et al., 1988). Moreover, many of these studies involve markets, which do not represent situations most likely to elicit differences in subject pools (Roth et al., 1991). On the basis of an extensive survey

\footnotetext{
${ }^{1}$ For instance, there are only 9 professionals in Burns (1985), 7 in DeJong et al. (1988), and 8-10 in Dyer et al. (1989).
} 
Ball and Cech (1993, pp. 31-32) conclude: "The combined evidence (...) seems to suggest that, in environments where probability and risk play a major role, research using students subjects has the potential to produce anomalous results and efforts should be made to replicate results using subjects from more representative populations." For all these reasons, replications with professionals, particularly concerning institutional settings other than markets, are called for.

In this paper, we report on a replication of the signaling game experiment referred to above, using professionals (and additional students) as subjects. The professionals were experienced public affairs officials, who voluntarily participated in the experiment while attending a conference on public affairs. To the best of our knowledge, this is the first study of subject surrogacy involving a signaling game. Moreover, this study differs from earlier investigations with respect to the relatively large number of professionals (30), and the use of "adequate" monetary rewards (see section 3).

For a number of reasons related to findings in the literature on subject-pool effects, significant differences in the behavior of professionals and student subjects may be expected in our case. Firstly, there is evidence suggesting that professionals go differently about risk and probabilities, which play a major role in our experiment (see above citation from Ball and Cech, 1993)2. In this context, it is noted that in the experiment a higher degree of risk-aversion should have an unequivocal effect on subject's behavior, as there are relatively save and risky choices for senders as well as responders. Secondly, the experimental game is a relatively complex one. It involves incomplete information, interaction, a relatively large strategy set, and the absence of dominated strategies. Since public affairs officials may be expected to feel more familiar with such an environment, which mimics some basic features of their "natural habitat", it provides an opportunity to them to behave differently. Experimental evidence suggests that more complex situations are indeed necessary for professionals to show different behavior (see Abdolmohammadi and Wright, 1987). Finally, the finding reported in Ball and Cech (1993, p. 16) that professional negotiators in an experiment were able to achieve outcomes with significantly greater joint value may also be relevant for our experiment. To see this it suffices to note here that our signaling game exhibits a dilemma structure: the equilibrium outcome of the game is payoff dominated by a "cooperative" (non-equilibrium) outcome. In the equilibrium outcome the responder is sometimes misinformed by the sender, and the responder's choices accommodate to that fact. In terms of expected payoffs this equilibrium outcome is worse for both the sender and the responder than the "cooperative"

\footnotetext{
${ }^{2}$ Ball and Cech (1993) report one finding, by Anderson and Sunder, where professional traders in an experimental auction turned out to be more risk-averse and more accurate in estimating probabilities than students. On the other hand, they also refer to Dyer et al.(1989) who believe that the professionals in their auction showed risk-neutrality, whereas the students exhibited risk-aversion.
} 
outcome. In case of the latter a sender reveals his private information to the responder, enabling the responder always to make the choice which is best for her. This outcome is only attainable, however, if the sender can somehow resist the temptation to cheat from time to time. Professional rules of conduct may help produce such resistance. In the literature on lobbying it is often suggested that one of the basic rules of lobbying is not to cheat or misinform for short term gains (Schlozman and Tierney, 1986). If our professional subjects brought such rules of conduct into the experiment, the game structure allowed them to be applied.

The paper is organized as follows. Section 2 describes the signaling game and its theoretical properties, and presents the hypotheses to be tested. Experimental procedures are discussed in section 3. Section 4 contains the experimental results and the tests of the hypotheses. Section 5 concludes.

\section{Game and hypotheses}

The signaling game underlying our experiment has two players: a sender $\mathrm{S}$ and a responder $\mathrm{R}$ (in the experiment neutrally labeled as participant $\mathrm{A}$ and $\mathrm{B}$, respectively). The latter has to decide between two choices, labeled B1 and B2. The payoffs received by R and S are determined by the choice selected by $\mathrm{R}$ and the realization of a stochastic state variable $\mathrm{k}$ (in the experiment, the color of a disc), which can take the value white or black. The realization of this variable is private information to $S$; $R$ only knows the prior odds that the value of $\mathrm{k}$ is white $(2 / 3)$ or black $(1 / 3)$. After the realization of $\mathrm{k}$, but before $\mathrm{R}$ makes her decision, $\mathrm{S}$ has to decide whether or not to send a message to R. Sending a message bears a fixed cost, c, to $\mathrm{S}$ only. Sending no message is costless. In case $S$ decides to send a message, he has to select the content of the message, which can be either "the color is white" or "the color is black". After R is informed about the 'signal' by $\mathrm{S}$ (no message, "white", or "black"), R chooses between B1 and B2.

We decided to focus on two parameter configurations (treatments). In treatment $\mathrm{L}$ the cost c of sending a message is relatively low (0.5 Dutch guilders for students, 2 guilders for professionals), whereas in treatment $\mathrm{H}$ this cost is relatively high (1.5 guilders for students, 6 guilders for professionals). ${ }^{3}$ The game-theoretic predictions of the effect of the cost differential are clear-cut and will be explained below. The payoffs in guilders to $\mathrm{R}$ and $\mathrm{S}$ as a function of the choice by $\mathrm{R}$ (B1 or B2) and the value of $\mathrm{k}$ (white or black) are shown in Table 1. The sender's payoffs differ

\footnotetext{
${ }^{3}$ In the next section it will be discussed why we have chosen to multiply the message cost, as well as the payoffs, for the professional subjects by 4 .
} 
per treatment. If we had only changed the cost to S of sending a message, the expected (equilibrium) payoffs to $\mathrm{S}$ would have been different in the two treatments, and also different from R's expected payoff in at least one treatment. To give the game-theoretic predictions their best chance, by mimimizing the potential effects of motivations like fairness or altruism, we chose to have a design where the expected equilibrium payoffs are the same over the two players' roles and over the two treatments.

Table 1. Payoffs for treatments $\mathrm{L}$ and $\mathrm{H}$ (in brackets) with message costs 0.5 and 1.5 , respectively. All figures are in guilders, to be multiplied by 4 for the professionals.

\begin{tabular}{|c|c|c|}
\hline payoff S & B1 & B2 \\
\hline white & $2(1.5)$ & $4(3.5)$ \\
\hline black & $1(1.5)$ & $7(5.5)$ \\
\hline
\end{tabular}

\begin{tabular}{|c|c|c|}
\hline payoff $\mathrm{R}$ & $\mathrm{B} 1$ & $\mathrm{~B} 2$ \\
\hline white & 3 & 1 \\
\hline black & 0 & 1 \\
\hline
\end{tabular}

Note from the payoffs in table 1 that the players have a common interest when the color is black: both prefer B2. However, if the color is white their interests conflict: R prefers to play B1, but S (again) prefers R to play B2. This feature makes the game strategically interesting, and not at all trivial.

To indicate the game-theoretic predictions for the game, we introduce some notation first. Let $S$ 's strategy be denoted by $\sigma_{\mathrm{k}}(\mathrm{s})$. It represents the probability that $\mathrm{S}$ sends signal $\mathrm{s}$, with $\mathrm{s} \in\{\mathrm{n}, \mathrm{w}$,"b" $\}$, given the color $\mathrm{k} \in\{\mathrm{w}($ hite),b(lack) $\}$, where the signals $\mathrm{n}$, "w", and "b", stand for no message, "the color is white", and "the color is black", respectively. Furthermore, let R's strategy be denoted by $\rho(s)$, which represents the probability that the responder chooses B2 given R's signal s.

Focusing on sequential equilibria, it is first noted that every message ("w" or "b") sent with positive probability should have the same effect on the responders choice, that is, $\rho(" w ")=\rho(" b ")$. As the decision to send a message implies the fixed cost $\mathrm{c}$, no matter its content, the content itself ("w" or "b") is equivalent to cheap talk. For the equilibrium analysis of the game this implies that we can disregard the content of the message and proceed as if the signal space contains only two elements: no message (n) and a message $(m)$, with $\sigma_{k}:=\sigma_{k}(m)=1-\sigma_{k}(n), k=b, w$.

There is a sequential equilibrium for this game in which the sender never sends a message, $\sigma_{\mathrm{k}}=0, \mathrm{k}=\mathrm{w}, \mathrm{b}$. Since the two "types" of the sender pool in this equilibrium, the responder will base her choice on her prior beliefs and opt for choice $B 1$ : $\rho(n)=0$. As the sequential equilibrium 
concept does not restrict R's belief in case she might receive an off-equilibrium message, $\mathrm{R}$ is allowed to play B 1 in that event, that is, $\rho(\mathrm{m})=0$. However, the beliefs that support this equilibrium fail to pass the stronger refinements tests - like Universal Divinity (Banks and Sobel, 1989) - that have been proposed to restrict off-equilibrium beliefs. The intuition for this failure is that $\mathrm{R}$ should realize that a costly message is more likely to be sent by $\mathrm{S}$ when the color is black, because this sender type has a larger stake in trying to persuade $\mathrm{S}$ to choose B2.

It turns out that there is a unique sequential equilibrium that satisfies all of the refinements. For expositional reasons, we derive this equilibrium in an informal way (for formal proofs, see Potters and van Winden, 1992). First note that in both treatments S has a larger stake in trying to persuade $\mathrm{R}$, by sending a costly message, when the color is black. Hence we have that $\sigma_{\mathrm{b}}>\sigma_{\mathrm{w}}$, as perfect pooling via $\sigma_{\mathrm{w}}=\sigma_{\mathrm{b}}=1$ cannot be optimal (for in that case a message would reveal no information to $R$ and thus lead to $\rho(m)=0$ ). Realizing that a message is more likely to be sent when the color is black, and no message when the color is white, $R$ will respond with $\rho(m)>\rho(n)=0$. Obviously, $\rho(m)=1$ cannot hold, because then each sender type would like to send a costly message for sure. Hence, we must have that $0<\rho(m)<1$, which requires that the responder is indifferent between choosing B1 or B2 when a message is received. Now, given a positive response by $\mathrm{R}$ to a costly message, it should follow that $\sigma_{b}=1$ whenever $\sigma_{w}>0$, because $S$ has a strictly larger stake in sending a message when $k=b$. Hence, we must have that $\sigma_{b}=1>\sigma_{w}>0$, since $\sigma_{\mathrm{w}}>0$ is required to make the responder indifferent. But this implies that the sender should be indifferent between sending a message and not sending a message, when $\mathrm{k}=\mathrm{w}$. It is straightforward to verify that these conditions can be satisfied simultaneously if and only if $\sigma_{w}=1 / 4$, in both treatments, and $\rho(m)=1 / 4$ in treatment $L$ and $\rho(m)=3 / 4$ in treatment $H$. It follows that increasing the cost to the sender of sending a message should (only) have a positive impact on the receiver's response to a costly message.

Summarizing we have the following equilibrium predictions:

Treatment L(ow cost): $\sigma_{\mathrm{w}}=1 / 4, \sigma_{\mathrm{b}}=1, \rho(\mathrm{n})=0, \rho(\mathrm{m})=1 / 4$

Treatment H(igh cost): $\sigma_{\mathrm{w}}=1 / 4, \sigma_{\mathrm{b}}=1, \rho(\mathrm{n})=0, \rho(\mathrm{m})=3 / 4$

The expected equilibrium earnings are 2 guilders for students and 8 guilders for professionals, irrespective of the role of the player and the treatment. For later reference it is added here that the "cooperative" outcome referred to in the previous section (implying that $\sigma_{w}=0, \sigma_{b}=1, \rho(n)=0$ and $\rho(m)=1$ ) would raise earnings to 2.33 for students and 9.33 guilders for professionals; that is, except for senders in treatment L, whose earnings would be equal to 3.5 and 14 guilders, respec- 
tively.

Having described the nature of the game and its equilibrium outcomes, we are now in the position to formulate our hypotheses. We start out with some general hypotheses concerning the qualitative aspects of the sequential equilibrium predictions. Although the goal of this paper is to study subject-pool effects, these hypotheses are of interest in themselves, and they prepare the ground for the main hypotheses. We do not focus on the quantitative "point predictions" because these values are derived under the assumption of strict selfishness and risk neutrality. The qualitative aspects of these predictions are not, or at least to a much lesser extent, dependent on the actual payoff and risk attitudes of the players. Since strategies cannot be directly observed, we will use the empirical frequency with which a message is sent in case of color $\mathrm{k}$ (denoted by $\mathrm{s}_{\mathrm{k}}$ ), and the empirical frequency with which B2 is chosen in case of signal s (denoted by $\mathrm{r}(\mathrm{s})$ ).

\section{General Hypotheses}

Content message: The response to a costly message is independent of its content: $r(" w ")=r(" b ")$.

Signaling: (i) Senders engage in costly signalling, with $\mathrm{s}_{\mathrm{b}}>\mathrm{s}_{\mathrm{w}}$; (ii) responders are influenced by costly signals: $r(m)>r(n)$.

Treatment effect: Only the impact of a message increases with its cost: $\mathrm{r}(\mathrm{m})_{\text {Treat } \mathrm{H}}>\mathrm{r}(\mathrm{m})_{\text {Treat } \mathrm{L}}$.

In this study we are particularly interested in the extent to which these hypotheses apply differently to students and professionals. For the formulation of our main hypotheses an important observation in the literature is that differences between the behavior of students and professionals are typically small and insignificant. As mentioned in the Introduction, counterevidence has been mainly attributed to the following factors: familiarity (field-experience) with the environment, a different risk-attitude, and rules of conduct developed in the field. The first factor, in particular the familiarity with strategic information transmission, could show up in (gamesmen-like) behavior by professionals that is more closely in line with the game-theoretic predictions than the behavior of students. The second factor could reinforce this behavioral difference to the extent that professionals are less risk-averse (more risk-neutral), as suggested by Dyer et al. (1989). A lesser degree of risk-aversion could show up in the experimental data as follows. For senders the more risky behavior is to send messages, which bear a fixed cost while the benefits are uncertain. For 
responders the more risky option is to choose B1, because the payoff of this choice is uncertain ( 3 or 0 ), whereas the payoff of choice B2 is always 1 . Hence, if students are more risk-averse we would expect them to opt more frequently for sending no message and choosing B2 than professionals. Rules of conduct, finally, could manifest themselves in the following two ways. Firstly, as discussed in the previous section, the "don't cheat for short-term gains rule" could make the "cooperative" outcome a greater attractor than the payoff dominated sequential equilibrium outcome. If so, this should show up in the earnings of the professionals in the experiment. Secondly, the emphasis in the lobbying literature on monitoring the reactions of the opponents (Strauch, 1993) could, if active as a rule among the professionals, show up in a stronger response to experience in the experiment than the response exhibited by students. The aforegoing discussion leads to the following hypotheses.

\section{Main Hypotheses}

Subject-pool effects: Any differences between the two subject-pools will manifest themselves in one or several of the following ways for the professional subjects in comparison with the student subjects: (a) behavior that is closer to the sequential equilibrium outcome (gamesmen behavior), (b) a different risk-posture, (c) behavior that is closer to the "cooperative" outcome (cooperative behavior), or (d) a stronger behavioral response to what is experienced in the experiment.

After the discussion of the experimental procedures in the next section, these hypotheses will be tested in section 4.

\section{Experimental procedures}

In total 15 experimental sessions were conducted, 12 of which with students as subjects and 3 with professionals. In total 142 students (S) and 30 professionals (P) participated. Six of the student sessions concerned the low cost (L) treatment (denoted by SL1-SL6), and the other six the high cost $(\mathrm{H})$ treatment (SH1-SH6). Two of the sessions with professionals were conducted under the low cost treatment (PL1 and PL2), and one under the high cost treatment (PH1). Table 1 showed the payoff parameters. Each session had 10 or 12 subjects as players and one subject to perform the role of monitor (observer). Table A1 of the Appendix provides some summary information regarding the sessions. All the sessions with professionals - which took place at a conference 
center - were of the "pen and paper" type. In case of the students four of the six sessions under each treatment were also conducted with pen and paper. The main reason was that we did not have a computerized laboratory at the time of the first sessions. The remaining two student sessions under each treatment were conducted by computer in the CREED-laboratory in Amsterdam. Of course, procedures were duplicated as much as possible. This appeared to be successful, since no significant differences were found between the two modes of conducting the experiment (if anything, slightly more "cheating" messages were sent in the computer mode).

Student subjects were recruited among the undergraduate student population of the University of Amsterdam. In announcements they were requested to participate in a two-hour experimental study of decision making which would earn them money. The majority of the participants were economics majors.

After a short introduction in the reception room, the student subjects were randomly assigned a role (sender, responder, or monitor) by picking an envelope which contained the role. Once the subjects and the monitor were seated in the laboratory - at tables with partitions - the instructions were distributed and read aloud (an English translation of the instructions is provided in the Appendix). In the instructions senders and responders were, respectively, called A and B participants. The message character of the sender's signal was retained in the experiment. Senders had to decide to send a message ("white" or "black") or to send "no message". Responder's choices were labeled B1 and B2. The student sessions consisted of 2 parts, each part beginning with one practice period followed by 10 periods (rounds) of play. Instructions for the second part were read only after the first part was finished. The only difference between the parts was that subjects changed roles (senders became responders, and vice versa). Because of the time constraint at the conferences where the sessions with the professionals were held (see below), we were not able to conduct this second part with the professionals. Therefore, only the data of part 1 of the student sessions will be used for comparison with the professionals.

The professional subjects were recruited among the subscribers to two different conferences on public affairs, one held in Amsterdam (PL1) and the other in The Hague (PL2 and PH1). They were informed by mail that participation in a one-hour experimental study of decision making, which would earn them money, was optional. Participants were executives and, in particular, public affairs and public relations officers from the private and the public sector. Experimental procedures were identical to those of the student sessions, except that the sessions with professionals were held in a conference room. Moreover, we quadrupled their payoffs and message costs. The payoffs in table 1 are based on the convention in experimental economics that subjects should, on average, at least be paid the opportunity cost of participation. The expected 
equilibrium earnings of 20 guilders in one hour (10 rounds of play, with an expected payoff of 2 guilders per play) are above the 15 guilders that a student would typically earn per hour in an odd job, such as working in a bar or restaurant. For the professionals, comparable monetary incentives were less easy to determine in view of the fact they had already subscribed to participate in the conference before signing up for the experiment. After consulting a public affairs consultancy firm, that was involved in the organization of one of the conferences, it was decided to multiply the payoffs and message cost by four. As a result, their expected equilibrium earnings were 80 guilders for one hour.

All subjects (students and professionals) participated only once, and no one had previously taken part in a similar experiment.

After the instructions were read the procedures were as follows. In every period each sender was matched with a responder. Subjects could not know whom they were matched with in any period. The matching scheme was determined randomly before the experiment under the constraint that no match would stay the same for two (or more) consecutive periods, nor occur more than twice during the ten periods. Subjects were informed about this constraint. Moreover, the matching scheme was handed out to the monitor, so that (s)he could check the procedure if (s)he so desired. In each period the game presented in the previous section was played according to the following rules. At the start of the period a white or black disk (checker) was drawn by the monitor from an urn. Whereas all subjects knew that the urn contained one black and two white disks, the disk drawn by the monitor was only revealed to the subjects playing the role of sender. After seeing the color of the disk a sender decided whether or not to send a message to the unknown responder he or she was paired with in that period. In case of a message, the sender had to choose between the announcement (the disk is) "white" or "black". Sending a message involved a fixed cost for the sender (as indicated in table 1). After the sender had recorded her or his decision, it was privately communicated to the responder, and the responder had to choose between B1 and B2. This choice was then communicated privately to the sender and the color of the disk was revealed to the responder (by the monitor). Results for the other pairs of subjects were not revealed.

Possible payoffs were presented in tables (see Appendix) and expressed in guilders. They were also projected on a wall, for all to see. Earnings were privately paid in cash at the end of the experiment, after the completion of a questionnaire.

The only difference between the sessions with professionals and students was that, after ten periods of play, students changed roles and proceeded with another ten rounds of play (without knowing that they would do so until after the completion of the first ten periods). The only 
difference between the computer sessions and the pen and paper sessions was that messages and choices were communicated to the other player by the computer in the former, and by us in the latter (by marking the appropriate columns on subjects' record sheets). In both types of sessions the monitor could check, using the matching scheme, whether the decisions made by the subjects corresponded with those communicated.

\section{Results}

In this section we discuss the experimental results in relation to the hypotheses formulated in section 2. A principal question to be addressed first, is what to take as an observation. There are three possibilities: each play of the game, each individual subject, or each session. In total we have 15 sessions, with in each session 10 rounds of a particular game, played by either 5 (sessions PL1, PL2, PH1 and SH4) or 6 pairs of subjects (SL1-SL6, SH1-SH3, SH5 and SH6). Hence, there are 15 session level observations, 172 subject level observations, and 860 game level observations. Because of the possibility of dependency of observations between periods and between subjects in one session, we will use the observations at the session level for the tests of our hypotheses. ${ }^{4}$

We start with testing the general hypotheses presented in section 2, concerning the impact of the content of messages, the occurrence of signaling, and treatment effects.

\section{General Hypotheses}

Content message. As empirical observations of the strategies in the game $-\sigma_{\mathrm{k}}(\mathrm{m}), \rho(\mathrm{n})$ and $\rho(\mathrm{m})$, with $k=b, w$ and $m=" b ", " w "$ - we use the corresponding observed frequencies, denoted by $s_{k}(m)$, $r(n)$ and $r(m)$. Table A2 of the Appendix presents these frequencies for each of the 15 sessions, aggregated over individual subjects and periods.

Comparing the frequencies with which B2 was chosen after a "black" message, r("b"), and a "white" message, $r(" w ")$, it turns out that the difference is positive and significant (at $p=.019$ ), using a two-tailed Wilcoxon (matched-pairs signed-ranks) test. Thus, contrary to the hypothesis, it seems that responders did not consider the content of a message as cheap talk. In fact, they had good reason for this because relatively more "white" messages were sent in case the color was white. Why senders did so is unclear. To the extent that they tried to mislead the responder, by

\footnotetext{
${ }^{4}$ Although using session aggregates yields relatively conservative tests, the conclusions do not change if another observation level is selected.
} 
suggesting that they would not be so stupid to send a "white" message if the color was indeed white, their strategy was not very successful. An alternative explanation could be that they were partly motivated by a feeling of guilt, arguing "I send a message, but I tell the responder that the color is white; so if he misinterprets I should not be blamed!".

However, the fraction of "white" messages is rather small (.14 for both students and professionals), and appears to diminish with increased experience. ${ }^{5}$ Therefore, and because of the fact that our results stay basically the same when either we leave these messages out or aggregate them with the other messages, no distinction in content will be made in the following (using $\mathrm{s}_{\mathrm{k}}:=\mathrm{s}_{\mathrm{k}}(\mathrm{m})$ and $\mathrm{r}(\mathrm{m})$, with $\mathrm{m}$ either "b" or "w").

Signaling. From tables 2 and 3 it is evident that senders engaged in costly signaling $\left(\mathrm{s}_{\mathrm{b}}>\mathrm{s}_{\mathrm{w}}\right)$, and that responders reacted in the expected direction to these signals $[\mathrm{r}(\mathrm{m})>\mathrm{r}(\mathrm{n})]$. The average frequency of messages was .732 in case the color of the disk was black $\left(\mathrm{s}_{\mathrm{b}}\right)$, and .460 when the color was white $\left(\mathrm{s}_{\mathrm{w}}\right)$. The difference is significant at $p=.001$, using a two-tailed Wilcoxon test with session aggregates as observations. Responders chose B2 at a rate of .389 when they received a message $[\mathrm{r}(\mathrm{m})]$, and at a rate of .068 when they received no message $[\mathrm{r}(\mathrm{n})]$. Using the same test, the difference is again highly significant $(p=.001)$.

Table 2. Frequencies of messages when the color was white $\left[\mathrm{s}_{\mathrm{w}}\right.$, first entry] or black [ $\mathrm{s}_{\mathrm{b}}$, second entry], averaged over the session aggregates, with standard deviations between brackets.

\begin{tabular}{c|c|c|c}
\hline \hline $\begin{array}{c}\mathrm{s}_{\mathrm{w}} \\
\mathrm{s}_{\mathrm{b}}\end{array}$ & L(ow cost) & H(igh cost) & row average \\
\hline professionals & $.515(.243)$ & $.343(.000)$ & $.457(.198)$ \\
& $.834(.047)$ & $.933(.000)$ & $.867(.067)$ \\
\hline$\ldots \ldots \ldots \ldots \ldots \ldots \ldots$ \\
students & $.549(.110)$ & $.373(.166)$ & $.461(.163)$ \\
& $.688(.117)$ & $.710(.108)$ & $.699(.108)$ \\
\hline column & $.540(.132)$ & $.368(.152)$ & $.460(.162)$ \\
average & $.724(.121)$ & $.742(.130)$ & $.732(.121)$ \\
\hline \hline
\end{tabular}

${ }^{5}$ It is noted that in relation to the content of the message no significant differences among the subject pools was found. 
Table 3. Frequencies of $B 2$ choices after no message $[r(n)$, first entry] and after a message $[r(m)$, second entry] averaged over the session aggregates, with standard deviations between brackets.

\begin{tabular}{c|c|c|c}
\hline \hline $\begin{array}{c}\mathrm{r}(\mathrm{n}) \\
\mathrm{r}(\mathrm{m})\end{array}$ & $\mathrm{L}($ ow cost $)$ & $\mathrm{H}(\mathrm{igh}$ cost $)$ & row average \\
\hline professionals & $.076(.006)$ & $.250(.000)$ & $.134(.101)$ \\
& $.267(.094)$ & $.654(.000)$ & $.396(.233)$ \\
\hline \multirow{2}{*}{ students } & $.061(.104)$ & $.042(.038)$ & $.052(.076)$ \\
& $.273(.106)$ & $.501(.105)$ & $.387(.156)$ \\
\hline column & $.065(.088)$ & $.071(.086)$ & $.068(.084)$ \\
average & $.272(.096)$ & $.523(.112)$ & $.389(.164)$ \\
\hline \hline
\end{tabular}

Treatment effect. According to our hypothesis, the higher cost of a message for the sender in treatment $\mathrm{H}$, in comparison with treatment $\mathrm{L}$, should (only) increase the impact of a message. This leads to the expectation that $\rho(\mathrm{m})_{\mathrm{H}}>\rho(\mathrm{m})_{\mathrm{L}}$, which is supported by the data. As table 3 shows, responders chose $\mathrm{B} 2$ at a rate of .523 after a message in treatment $\mathrm{H}$, and at a rate of .272 in treatment $\mathrm{L}$ (averaged over the sessions). The difference is significant at $p=.002$, using a two-tailed Mann-Whitney test.

Also in line with the hypothesis is that no significant treatment effect on the frequencies of $s_{b}$ and $r(n)$ is found, using the same test. However, with respect to messages in case the color was white $\left(s_{\mathrm{w}}\right)$ it turns out that these were sent at a significantly higher rate when the cost of doing so was relatively low. As table 2 shows, this frequency is .540 in treatment $\mathrm{L}$ and .368 in treatment $\mathrm{H}$ (averaged over the sessions). The difference is significant at $p=.029$. Apparently, senders send more messages when the cost $\mathrm{c}$ of doing so, relative to the potential benefit, is low. This relative cost equals $0.25=0.5 /(4-2)$ in treatment $\mathrm{L}$ and $0.75=1.5 /(3.5-1.5)$ in treatment $\mathrm{H}$ (see table 1 ). Although this outcome may seem rather intuitive, it was not to be expected on the basis of the game-theoretic analysis underlying our hypotheses.

The results presented so far are in line with our earlier experimental findings, which showed that the sequential equilibrium outcomes fail as precise predictions of the experimental results. The extent to which the results do support the equilibrium predictions is beyond the scope of the present paper. For a detailed analysis the reader is referred to our earlier paper (Potters and van Winden, forthcoming). We now turn to an investigation of the hypotheses concerning subject-pool effects, which are the main focus of this paper.

\section{Main Hypotheses}


The hypotheses relate to potential differences between students and professionals in terms of (a) gamesmen-like behavior, (b) risk-posture, (c) cooperative behavior, and (d) the behavioral response to experience. As discussed, greater familiarity with the environment could lead to behavior by professionals that is more in line with the game-theoric predictions. On the other hand, rules of conduct developed in the field might contribute to cooperation and a stronger impact of what is experienced in the experiment. Regarding the latter, behavioral rules developed in the field may cause professionals to display weaker adaptation and learning than students in an experimental environment (cf. Burns, 1985, Mestelman and Feeny, 1988). However, if the rule is to "closely monitor the feedback from decisionmakers", as suggested in the lobbying literature (Strauch, 1993), then professionals could actually exhibit a stronger reliance on experience than students. ${ }^{6}$ Given the lack of transparency of the institutional environment in which lobbying takes place such a rule is quite understandable.

(a) Gamesmen-like behavior. We first compare the behavior of the students and the professionals as represented by the - for each pool - observed frequencies $r(m), r(n), s_{b}$, and $s_{w}{ }^{7}$ Using again a two-tailed Mann-Whitney test, no significant differences are found, except for $\mathrm{s}_{\mathrm{b}}$. When the color was black, professionals sent messages at a significantly higher rate (.867 versus .699 , with $p=.031$ ). However, comparing the average prediction errors $\sigma_{\mathrm{k}}-\mathrm{s}_{\mathrm{k}}$ (with $\mathrm{k}=\mathrm{b}, \mathrm{w}$ ) and $\rho(\mathrm{s})-\mathrm{r}(\mathrm{s})$ (with $\mathrm{s}=\mathrm{n}, \mathrm{m})$, it turns out that this is not an indication of more gamesmen-like behavior, because no significant differences in these errors are found between the pools. ${ }^{8}$

(b) Risk-posture. The larger value of $\mathrm{s}_{\mathrm{b}}$ for professionals could point at less risk-aversion, because sending a costly message is the more risky option for the sender. This is not corroborated by the outcome for $\mathrm{r}(\mathrm{n})$, though. In case of less risk-aversion one would expect that, in the role of responder, professionals would choose significantly more often B1 after having received no message. The reason is that this is the more risky option for the responder in that situation. However, it turns out that $\mathrm{r}(\mathrm{n})$ is larger for professionals in both treatments, albeit at a significance level

\footnotetext{
${ }^{6}$ Strauch $(1993$, p. 45$)$ refers to this rule as one of the "methods of lobbying" ("Genaue Beachtung des Feedback von den Entscheidungsträgern").

${ }^{7}$ The significance levels with the general hypotheses show that 15 (session) observations are sufficient for nonparametric tests to pick up effects that are strong and systematic.

${ }^{8}$ For example, using the unweighed session averages over the four frequencies $\left[s_{w}, s_{b}, r(n), r(m)\right]$, the average absolute deviation from the theoretical predictions is somewhat lower for the 3 sessions with professionals (.138) than for the 12 sessions with students (.188), but the difference is not significant with a two-tailed Mann-Whitney test $(p=.180)$.
} 
of $p=.101$. This latter result points in the direction of greater risk-aversion for professionals. Thus, there appears to be no systematic evidence for differences in risk-attitude.

(c) Cooperative behavior. In case of more cooperative behavior one would anticipate $\mathrm{s}_{\mathrm{b}}$ to be closer to 1 , and $\mathrm{s}_{\mathrm{w}}$ to be closer to 0 , for the professionals. At any rate, one would expect higher payoffs for the professional senders and responders. As to the frequencies, we have already seen that only $s_{b}$ meets the expectation. With respect to the average payoffs no significant differences are found, although professionals did indeed earn more than students in both roles and treatments (the overall averages being 210 versus 186 guilders for senders, and 189 versus 175 guilders for responders, using the student payoff parameters for comparison). Moreover, in the role of responder, the students had higher expected earnings, calculated on the basis of the probability of the disc's color and the observed behavioral frequencies $\left[\mathrm{s}_{\mathrm{b}}, \mathrm{s}_{\mathrm{w}}, \mathrm{r}(\mathrm{m})\right.$ and $\left.\mathrm{r}(\mathrm{n})\right]$. It can be concluded, therefore, that the professionals did neither significantly nor systematically distinguish themselves from the students in terms of cooperative behavior.

(d) Response to experience. Subjects had full information on the decisions, colors, and earnings in the plays of the game they themselves participated in (thus, not regarding sender-responder pairs that they were no party to). We relate the behavior of the subjects to this information in the following two ways, which distinguish between belief learning and rote learning (Selten, 1991). Under the former type of learning subjects adjust their behavior to experience via its impact on their beliefs. More specifically, subjects are here hypothesized to increase the frequency of choices which are a best response to the aggregate history of play, using the observed frequencies of choices by opponents to update their beliefs about these choices. ${ }^{9}$ In case of rote learning a simple stimulus-response process is assumed. In that case subjects are hypothesized to increase (decrease) the frequency of choices which turned out to be successful (unsuccessful) in the previous round of play, where success is defined by higher earnings than in the immediately preceding round of play $(\mathrm{t}-2){ }^{10}$

\footnotetext{
${ }^{9}$ For each sender in a particular period $t$ we calculate the cumulative frequencies of $r(m)_{t-1}$ and $r(n)_{t-1}$ up to that period. Then we determine whether the value of $r(m)_{t-1}-r(n)_{t-1}$ multiplied by the gain for the sender when B2 instead of B1 is chosen exceeds the cost of sending a message. If this is (not) the case, then (not) sending a message is the best response to history. For responders, using the cumulative frequencies of $s_{\mathrm{w}, t-1}$ and $s_{b, t-1}$ up to a period $t$, it is straightforward to check that in both treatments it is the best response to history for them to react to a message with B2 (B1) if $\mathrm{s}_{\mathrm{b}, \mathrm{t}-1} * 1 / 4>(<) \mathrm{s}_{\mathrm{w}, \mathrm{t}-1}$.

${ }^{10}$ Thus, for senders, if sending a message (no message) in the previous period earned them more (less) than in the preceding period ( $\mathrm{t}-2)$ this should increase the frequency with which messages are sent in period t; otherwise, this frequency should decrease. Similarly, for responders, if the choice of B1 (B2) in the
} 
We start with the cognitively more demanding learning model of "best response to history" (BRTH), which is closest in spirit to gamesmen behavior. Averaged over the sessions we find that a message was sent at a rate of .756 when it was BRTH to do so, and at a rate of .455 when it was BRTH not to do so. The difference is highly significant ( $p=.002$, Wilcoxon test). Furthermore, the magnitude of the effect is somewhat smaller for professionals (.232) than for students (.320), but the difference between the two subject pools is not significant. With respect to responders it turns out, pooling over sessions and treatments, that messages were reacted to with B2 at a rate of .371 when it was BRTH to react with B1, and at a rate of .580 when it was BRTH to react with B2. The difference is again significant $(p=.030)$. The magnitude of the effect is now smaller for students (.225) than for professionals (.411), but the difference between the two pools is again not significant. ${ }^{11}$ The conclusion is that there is significant evidence of belief learning, in the direction of BRTH, but no support for any significant or systematic subject-pool effects.

So what about rote learning? For the senders it turns out that, indeed, relatively more messages occurred when sending a message had been successful, or sending no message had been unsuccessful, in the previous round (.651 versus .522). The difference is not significant, however. The magnitude of the effect is a bit larger for professionals (.156) than for students (.122), but also this difference is not significant. For the responders we find that relatively less often B2 was chosen when this choice was successful or picking B1 turned out to be unsuccessful in the previous period (.140 versus .237). Although the difference is now significant ( $p=.041$ ), it is in the wrong direction. The magnitude of the effect is somewhat smaller for professionals (-.069) than for students (-.103), but this difference is again not significant. The conclusion is that there is no evidence of rote learning, and again no support for any significant or systematic subject-pool effects. $^{12}$

Summarizing, we only find support for belief learning in the direction of best response to history (as in our earlier study: Potters and van Winden, forthcoming) ${ }^{13}$, but no evidence of

previous period earned them more (less) than in the preceding round (t-2) this should increase the frequency of B1 choices in period t; otherwise, this frequency should decrease.

${ }^{11}$ It must be noted, however, that the session aggregates are sometimes based on few observations. This is due to the fact that the frequencies $s_{\mathrm{w}, t-1}$ and $\mathrm{s}_{\mathrm{b}, \mathrm{t}-1}$ can only be calculated if a responder has at least once experienced both a white and a black color.

12 This conclusion does not change when, for the definition of success, earnings obtained with a particular choice (action) in the previous period are compared with its average earnings up to that period.

${ }^{13}$ Interestingly, Cheung and Friedman (1995), analyzing learning models in a variety of normal form game experiments, find "overall somewhat better fits for fictitious play (long memory) learning than Cournot (short memory) learning". 
significant or systematic differences between the two subject-pools. This completes the investigation of our main hypotheses concerning subject-pool effects. Neither significant nor systematic effects were found. ${ }^{14}$

\section{Conclusion}

Our major conclusion is that there are neither significant nor systematic behavioral differences between the students and the professional subjects. Although we do find significant and systematic support for learning (contrary to, e.g., Dyer et al., 1989), there are also in this respect no traceable differences between the two subject-pools.

Of course, one could question whether the subjects, in particular the professionals, took the experiment seriously. Also, as a study of lobbying, one could argue that the experimental design perhaps eliminated essential aspects of the lobbying environment in the field (cf. in this context Dyer and Kagel, forthcoming, on the winner's curse). Although it is impossible to provide a definitive answer, we have the following arguments in support of our study.

Regarding the first issue, there is no indication from observations during or discussions after the experimental sessions, nor from responses to a debriefing questionnaire, that one should be worried about the seriousness with which subjects determined their decisions. For instance, the responses to the questionnaire showed that only 2 professional subjects found the experiment (a little) boring, and only 3 of them thought the possible earnings were low.

With respect to the experimental design we have the following arguments. First, comments collected during a seminar presented at a public affairs consultancy firm (before the experiment, but with different professionals) gave support to the relevance of the design. Of course, many other issues of interest were mentioned - such as repeated interaction - but that is more a matter of adding complexity to the experiment. Second, it is noted that there is at present a strongly felt need of professionalization in this field (this was also a central issue at the conferences where the experiments with the professionals were run). Our impression from discussions with public affairs consultants is that the many rules of thumb that are advertised are no longer found satisfactory. This makes it less surprising why no subject-pool effects were detected in the experiment. Though

\footnotetext{
${ }^{14}$ Apart from the above analyses we also compared the two pools in other respects, such as behavior in the first and last period(s), the degree of signaling $\left(\mathrm{s}_{\mathrm{b}}-\mathrm{s}_{\mathrm{w}}\right.$ and $\left.\mathrm{r}(\mathrm{m}) \mathrm{r}(\mathrm{n})\right)$, the average efficiency level (the relative number of times that responders made the "right" - i.e., payoff maximizing - choice), and the variance in behavior within the two pools. In none of these respects significant or systematic differences were found. With respect to variance in behavior it is noted that DeJong et al. (1989) found that businessmen generally exhibited greater variance in market behavior than students.
} 
the behavior of professionals may significantly differ when it comes to the use of social skills (important for contacting), for example, it need not differ in all situations of strategic information transmission that is at the heart of lobbying, as turned out to be the case for the environment studied in this experiment. 
Appendix. Information on sessions and instructions

Table A1. Session characteristics

\begin{tabular}{l|l|l|l|l|l}
\hline \hline session & treat $^{1}$ & pool $^{2}$ & \# subjects & mode $^{3}$ & date \\
\hline LP1 & low & prof & 10 & p\&p & $5 / 92$ \\
LP2 & low & prof & 10 & p\&p & $1 / 93$ \\
HP1 & high & prof & 10 & p\&p & $1 / 93$ \\
LS1 & low & stud & 12 & p\&p & $1 / 92$ \\
LS2 & low & stud & 12 & p\&p & $3 / 93$ \\
LS3 & low & stud & 12 & p\&p & $4 / 94$ \\
LS4 & low & stud & 12 & p\&p & $4 / 94$ \\
LS5 & low & stud & 12 & comp & $4 / 94$ \\
LS6 & low & stud & 12 & comp & $4 / 94$ \\
HS1 & high & stud & 12 & p\&p & $1 / 92$ \\
HS2 & high & stud & 12 & p\&p & $3 / 92$ \\
HS3 & high & stud & 12 & p\&p & $4 / 93$ \\
HS4 & high & stud & 12 & p\&p & $4 / 93$ \\
HS6 & high & stud & 12 & comp & $4 / 93$ \\
\hline \hline
\end{tabular}

${ }^{1}$ parameter treatment: low $=$ low cost high $=$ high cost

${ }^{2}$ prof $=$ professionals; stud $=$ students

${ }^{3} \mathrm{p} \& \mathrm{p}=$ pen and paper; comp $=$ computerized 
Table A2. Session data

\begin{tabular}{|c|c|c|c|c|c|c|c|}
\hline \multirow{2}{*}{ session } & \multicolumn{4}{|c|}{ senders } & \multicolumn{3}{|c|}{ responders } \\
\hline & $\mathrm{s}_{\mathrm{w}}(" \mathrm{w} ")$ & $\mathrm{s}_{\mathrm{w}}(" \mathrm{~b} ")$ & $\mathrm{s}_{\mathrm{b}}(" \mathrm{w})$ & $\mathrm{s}_{\mathrm{b}}(" \mathrm{~b} ")$ & $\mathrm{r}(\mathrm{n})$ & r("w") & r("b") \\
\hline LP1 & $.029(1 / 35)$ & $.314(11 / 35)$ & $.067(1 / 15)$ & $.800(12 / 15)$ & $.080(2 / 25)$ & $.000(0 / 2)$ & $.217(5 / 23)$ \\
\hline LP2 & $.114(4 / 35)$ & $.571(20 / 35)$ & $.067(1 / 15)$ & $.733(11 / 15)$ & $.071(1 / 14)$ & $.000(0 / 5)$ & $.387(12 / 31)$ \\
\hline HP1 & $.086(3 / 35)$ & $.257(9 / 35)$ & $.067(1 / 15)$ & $.867(13 / 15)$ & $.250(6 / 24)$ & $.750(3 / 4)$ & $.636(14 / 22)$ \\
\hline LS1 & $.104(5 / 48)$ & $.479(23 / 48)$ & $.167(2 / 12)$ & $.417(5 / 12)$ & $.000(0 / 25)$ & $.000(0 / 7)$ & $.286(8 / 28)$ \\
\hline LS2 & $.083(4 / 48)$ & $.396(19 / 48)$ & $.083(1 / 12)$ & $.500(6 / 12)$ & $.267(8 / 30)$ & $.000(0 / 5)$ & $.200(5 / 25)$ \\
\hline LS3 & $.125(3 / 24)$ & $.333(8 / 24)$ & $.056(2 / 36)$ & $.583(21 / 36)$ & $.000(0 / 26)$ & $.200(1 / 5)$ & $.172(5 / 29)$ \\
\hline LS4 & $.083(3 / 36)$ & $.500(18 / 36)$ & $.000(0 / 24)$ & $.875(21 / 24)$ & $.000(0 / 18)$ & $.333(1 / 3)$ & $.333(13 / 39)$ \\
\hline LS5 & $.119(5 / 42)$ & $.619(26 / 42)$ & $.000(0 / 18)$ & $.778(14 / 18)$ & $.067(1 / 15)$ & $.000(0 / 5)$ & $.500(20 / 40)$ \\
\hline LS6 & $.048(2 / 42)$ & $.405(17 / 42)$ & $.000(0 / 18)$ & $667(12 / 18)$ & $.034(1 / 29)$ & $.000(0 / 2)$ & $.310(9 / 29)$ \\
\hline HS1 & $.083(2 / 24)$ & $.208(5 / 24)$ & $.056(2 / 36)$ & $.500(18 / 36)$ & $.030(1 / 31)$ & $.250(1 / 4)$ & $.391(9 / 23)$ \\
\hline HS2 & $.167(6 / 36)$ & $.167(6 / 36)$ & $.000(0 / 24)$ & $.833(20 / 24)$ & $.000(0 / 28)$ & $.000(0 / 6)$ & $.731(19 / 26)$ \\
\hline HS3 & $.000(0 / 36)$ & $.111(4 / 36)$ & $.042(1 / 24)$ & $.667(16 / 24)$ & $.000(0 / 39)$ & $1.00(1 / 1)$ & $.550(11 / 20)$ \\
\hline HS4 & $.067(3 / 45)$ & $.444(20 / 45)$ & $.200(1 / 5)$ & $.600(3 / 5)$ & $.087(2 / 23)$ & $.000(0 / 4)$ & $.435(10 / 23)$ \\
\hline HS5 & $.083(1 / 12)$ & $.333(4 / 12)$ & $.063(3 / 48)$ & $.688(33 / 48)$ & $.053(1 / 19)$ & $.250(1 / 4)$ & $.622(23 / 37)$ \\
\hline HS6 & $.214(9 / 42)$ & $.357(15 / 42)$ & $.056(1 / 18)$ & $.556(10 / 18)$ & $.080(2 / 25)$ & $.300(3 / 10)$ & $.600(15 / 25)$ \\
\hline
\end{tabular}

Senders: $s_{k}(" w ")\left[s_{k}(" b ")\right]$ gives the frequency of "white" ["black"] messages when the true color is $k$, with $k=w(h i t e)$ or $\mathrm{b}\left(\right.$ lack); the frequency of messages ("white" or "black"), $\mathrm{s}_{\mathrm{k}}:=\mathrm{s}_{\mathrm{k}}(" \mathrm{w} ")+\mathrm{s}_{\mathrm{k}}(" \mathrm{~b}$ "), is our main focus in the text.

Reponders: $\mathrm{r}(\mathrm{s})$ gives the frequency of B2 choices after a signal s, $\mathrm{s}=\mathrm{n}(\mathrm{o}$ message) "w(hite)", or "b(lack)"; $\mathrm{r}(\mathrm{m})$, the frequency of B2 choices after a message ("white" or "black"), is a weighed average of $r(" w ")$ and $r(" b ")$ and is our main focus in the text. 
The following is an exact translation from Dutch of the instructions for the pen and paper sessions.

\section{INTRODUCTION}

You are about to participate in an experimental study of decision making. The experiment consists of two parts. In total the experiment will last about 2 hours. Before you will be invited to the laboratory, we ask you to draw one envelope from this box.

In the envelope you will find your "registration number", which will be used throughout the experiment, and an indication of your role in the first part of the experiment. There are two roles: "participant A" and "participant B". In the envelope it is announced whether you have the role of participant A or B. One envelope is an exception to this rule. Instead of "participant A" or "participant B" this envelope contains the announcement "monitor". The monitor will watch us while we carry out the experiment and assist us from time to time. The monitor receives a payment of 40 guilders.

After you have taken an envelope, you are invited to enter the laboratory and take a seat behind a table reserved for an A or B participant. As you will see clearly indicated, participants A sit together in one part and participants B in another part of the room. A separate table is reserved for the monitor.

From the moment you have drawn an envelope you are no longer allowed to talk or communicate to the other participants. If you have a question, please raise your hand and one of us will come to your table. As soon as everyone has taken his or her seat in the laboratory, we will distribute further instructions and read them aloud.

Are there any questions about what has been said up till now? If not, then the person on the left of me is now requested to first pick an envelope, open it and go to the laboratory.

\section{INSTRUCTIONS}

$\underline{\text { Introduction }}$

This is an experimental study of decision making. Various research institutions have provided funds for this study. The instructions are simple and if you follow them carefully you may earn a considerable amount of money. All the money you earn is yours to keep. Your payoffs will be paid to you in cash, privately and confidentially, after the experiment.

We will begin by reading these instructions. Thereafter you will have the opportunity to ask questions.

\section{$\underline{\text { Decisions and earnings }}$}

The experiment will consist of two separate parts, and each part will consist of a number of periods. In each period a participant $\mathbf{A}$ will be matched with a participant $\mathbf{B}$. Both participants will have to take one decision during the period. The earnings for $\mathrm{A}$ and $\mathrm{B}$ depend upon the decisions made, but are codetermined by the color of a disk. The color of the disk can be either black or white. At the beginning of each period the color of the disk will be determined by a drawing. The probability that a white or a black disk is drawn will be announced to both participants. The outcome of the drawing, however, will only be announced to participant A. Hence, participant A knows the color, whereas B only knows the probabilities of a white and a black disk. At the beginning of each period participant $\mathrm{A}$ decides whether or not to send a message to participant B. In case of a message, there is a choice between the announcement (the disk is) "white" and the announcement (the disk is) "black". The announcement is allowed to differ from the real color. Sending a message bears a cost to participant A; the costs of a message will be stated in guilders.

Thus, the decision by participant A can either be a message, stating "white" or "black", or no message. This decision will then be communicated to participant B. Each B participant will be notified of only one decision, namely, the decision of the A participant to whom he or she has been matched in that period. After taking notice of A's decision, participant B decides whether to react with choice B1 or choice B2. This decision (choice) will then be communicated to participant A and, finally, the color of the disk will be announced to $\mathrm{B}$.

The earnings of $\mathrm{A}$ and $\mathrm{B}$ are (apart form the costs of a message) determined by the disk's color 
(white or black) and B's decision. These earnings are presented in tables on the sheet called DESCRIPTION, which has already been distributed. You are now requested to take this sheet. In order to demonstrate that all of you have the same information, this sheet will also be projected on the wall.

First, you see the probabilities that the disk's color is white or black. Next, it is again indicated that participant A takes a decision whether or not to send a message, before participant B determines her or his choice. In case of a message, a choice must be made between the announcements "white" and "black". The costs of a message are posted in guilders.

Finally you see two tables. The left table presents A's earnings and the right one presents B's. If you want to know a participant's earnings with a particular color of the disk and a particular choice by B, you first move to the table indicating "earnings participant $A$ " or "earnings participant $B$ ". Then you look up the color of the disk (white or black) and you move to the right to the column indicating the choice of $\mathrm{B}$ (choice B1 or choice B2). The figures are stated in guilders. For A participants the costs of a message must be subtracted if a message was sent.

\section{The monitor}

At the beginning of each period the monitor will perform the drawing that determines the color of the disk. This color will then privately be communicated to the A participants.

From time to time we will ask the monitor whether we are actually conducting the experiment in the manner specified in the instructions. The monitor will be expected to answer these questions with a simple yes or no. The monitor will also assist us with the experiment. The monitor will not be permitted to communicate with the rest of you in any way.

The monitor is now requested to show the disks to the participants, in order to check whether the probability of a white and a black disk is in accordance with the probabilities stated on the sheet DESCRIPTION. [There always was one black disk and either one or two white disks. We also asked the monitor to show the urn and filmcases for the disks and to turn them upside done.]

$\underline{\text { Recording of the results }}$

Now both A and B participants are requested to pick one envelope from the appropriate box and to open the envelope.

Take the enclosed sheet, called RECORD SHEET, and put your registration number in the upper left corner. The registration number is needed to make sure that the right payments are made to the right person. On the next line you see your role (A or B) in this part of the experiment. The table is also projected on the wall.

Now, first look at the first (left) column of the table. The figures in this column indicate the period, starting with period 0 and ending with period 10. Period 0 is a practice period. The results (earnings) of this period are not included in the payments at the end of the experiment.

The next column (the second from the left) contains a codeletter. This codeletter makes it easier for us to register the results. The codeletter determines the participant in the other role you are matched with in a particular period. Each period you are matched with a different person; furthermore, in periods 1 to 10 you are matched with the same person at most twice. We have determined the sequence before the experiment in an arbitrary way, so you cannot know whom you are matched with in a any period.

Each period will proceed as follows. After the color has been determined by the monitor's draw, this color will be communicated to the A participants. They will mark this color in the column called "the color is" of their RECORD SHEET. Then participant A takes her or his decision to send or not to send a message ("white" or "black") to B. Participant A will mark this decision in the column called "A's decision (message)". We will then note this decision on the RECORD SHEET of the appropriate B participant. Participant B will then make her or his decision (choice B1 or choice B2) and mark it in the column "B's decision". We will then note this decision on A's sheet and simultaneously, the monitor will mark the color of the disk in the column "the color is" of the B participants.

The last two columns concern the payoffs. At the end of each period you will use the tables of the sheet DESCRIPTION to determine your payoffs for that period. These payoffs must be noted in the column called "your payoffs". Finally, for the sake of completeness, a column is included in which you are supposed to register the payoffs of the participant with whom you are matched in a particular period. For A 
participants account must be taken of the costs of a message in case A has decided to send a message in that period.

We will also register all the information.

$\underline{\text { Summary }}$

Each period begins with the monitor drawing the color of the disk. After the outcome has been communicated to participant $\mathrm{A}$, he or she decides whether or not to send a message to participant B. After this decision has been communicated, it is B's turn to take a decision (choice B1 or choice B2), not knowing the result of the draw (the disk's color). Finally, B's decision is communicated to A and the disk's color to B. With this information the participants determine the payoffs for that period, on the basis of the tables on the sheet DESCRIPTION. The next periods will proceed in exactly the same way until and including period 10 . be read.

Thereafter, the sheets for part 2 of the experiment will be distributed, and the new instructions will

\section{Final Remarks}

At the end of today's session you will be asked to answer some questions for the evaluation of the experiment. After that you will be called by your registration number to privately collect your payoffs in cash at the secretariat. Your payoffs are your own business: you don't have to discuss them with anyone.

It is not allowed to talk or communicate with other participants during the experiment. If you have any questions please raise your hand and one of us will come to your table. 


\section{DESCRIPTION}

(sample treatment L)

- $\quad$ The urn contains two white disks and one black disk. Hence, the probabilities that a white is drawn is $\mathbf{2 / 3}$ and the probability that a black disk is drawn is $\mathbf{1 / 3}$.

- $\quad$ Participant A decides whether or not to send a message - "white" or "black" - before participant B makes her or his choice. A message bears a cost of $\boldsymbol{f} \mathbf{0 . 5 0}$ to participant A.

- $\quad$ The earnings to participant A (excluding any message cost) and participant B are presented in the tables below. The earnings are dependent upon the disk's color (the color is white or the color is black) and B's decision (choice B1 or choice B2).

\begin{tabular}{|c|c|c|}
\hline $\begin{array}{c}\text { earnings } \\
\text { participant } A\end{array}$ & $\begin{array}{c}\text { choice } \\
\mathrm{B} 1\end{array}$ & $\begin{array}{c}\text { choice } \\
\mathrm{B} 2\end{array}$ \\
\hline $\begin{array}{c}\text { the color is } \\
\text { white }\end{array}$ & 2 & 4 \\
\hline $\begin{array}{c}\text { the color is } \\
\text { black }\end{array}$ & 1 & 7 \\
\hline
\end{tabular}

\begin{tabular}{|c|c|c|}
\hline $\begin{array}{c}\text { earnings } \\
\text { participant } B\end{array}$ & $\begin{array}{c}\text { choice } \\
\mathrm{B} 1\end{array}$ & $\begin{array}{c}\text { choice } \\
\mathrm{B} 2\end{array}$ \\
\hline $\begin{array}{c}\text { the color is } \\
\text { white }\end{array}$ & 3 & 1 \\
\hline $\begin{array}{c}\text { the color is } \\
\text { black }\end{array}$ & 0 & 1 \\
\hline
\end{tabular}




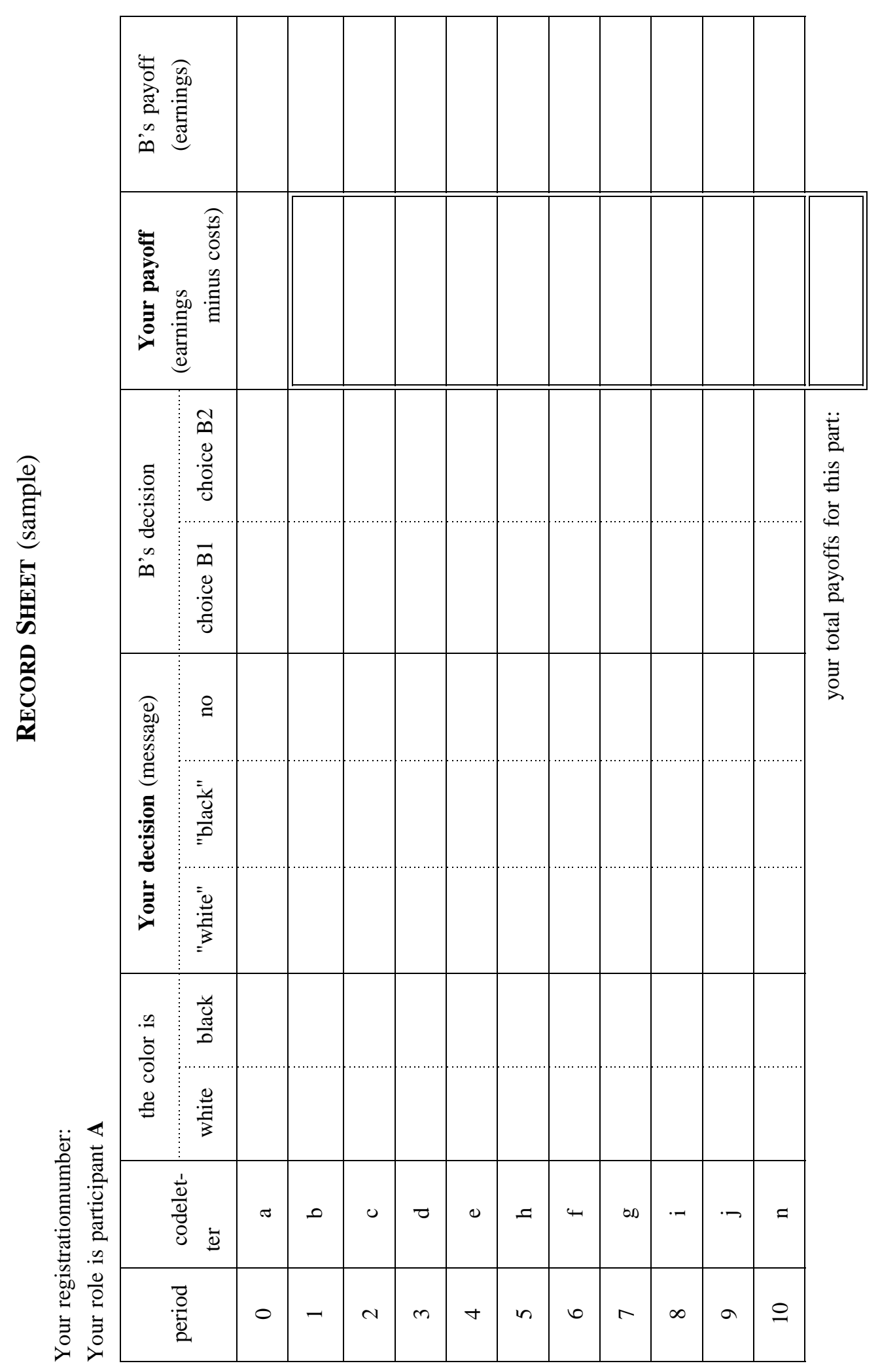




\section{Computerized sessions}

The instructions and design of the computerized sessions are identical to those of the pen and paper sessions except for the following:

All choices were made on, and communicated by, the computer.

The Description sheet with the payoff tables (see above) was projected on the computer screen throughout the experiment (and on the wall, as in the pen and paper sessions).

- $\quad$ The Record sheet (see above) was projected on the computer screen.

In the pen and paper sessions subjects had to calculate their own and their opponent's payoffs. We checked these calculations, which gave us information on whether they understood the game situation. In the computer sessions, the computer calculated the payoffs. To have a check on whether they understood the calculation, subjects had to answer four simple questions concerning the calculation of the payoffs before playing the game. For the same reason - forcing the subjects to look through the payoff tables -, two practice periods were held.

The debriefing questionnaire was per computer. 


\section{References}

Abdolmohammadi, M., and Wright, A. (1987), "An examination of the effects of experience and task complexity on audit judgements", The Accounting Review 62, 1-13.

Austen-Smith, D. (1994), "Strategic costly information", Econometrica 62, 955-963.

Ball, S.B, and Cech, P. (1993), "Subject pool choice and treatment effects in economic laboratory research", mimeo.

Burns, P. (1985), "Experience and decisionmaking: a comparison of students and businessmen in a simulated progressive auction", in V. Smith (ed.), Research in Experimental Economics, Vol. 3, Greenwich: JAI Press.

Cheung, Y-W., and Friedman, D. (1995), "Individual learning in games: some laboratory results", mimeo.

Davis, D., and Holt, C. (1993), Experimental Economics, Princeton: Princeton University Press.

DeJong, D., Forsythe, R., and Uecker, W. (1988), "A note on the use of businessmen in sealed offer markets", Journal of Economic Behavior and Organization 9, 87-100.

Dyer, D., and Kagel, J. (forthcoming), "Bidding in common value auctions: How the commercial construction industry corrects for the winner's curse", Management Science.

Dyer, D., Kagel, J., and Levin, D. (1989), "A comparison of naive and experienced bidders in common value auctions: A laboratory analysis", Economic Journal 99, 108-115.

Kinder, D., and Palfrey, T. (1993), "On behalf of an experimental political science", in D. Kinder and T. Palfrey (eds.), Experimental Foundations of Political Science, Ann Arbor: University of Michigan Press.

Mestelman, S., and Feeny, D. (1988), "Does ideology matter?: Anecdotal experimental evidence on the voluntary provision of public goods", Public Choice 57, 281-286.

Plott, C. (1982), "Industrial organization theory and experimental economics", Journal of Economic Literature 20, 1485-1527.

Potters, J., and van Winden, F. (1992), "Lobbying and asymmetric information", Public Choice 74, 269-292.

Potters, J., and van Winden, F. (forthcoming), "Comparative statics of a signaling game. An experimental study", International Journal of Game Theory. 
Roth, A., Prashnikar, V., Okuno-Fujiwara, M., and Zamir, S. (1991), "Bargaining and market behavior in Jerusalem, Ljubljana, Pittsburgh, and Tokyo: An experimental study", American Economic Review 81, 1068-1095.

Schlozman, K., and Tierney, J. (1986), Organized Interests and American Democracy, New York: Harper and Row.

Selten, R. (1991), "Evolution, learning, and economic behavior", Games and Economic Behavior 3, 3-24.

Strauch, M. (1993), Lobbying, Wiesbaden: Gabler. 